\title{
Increased B chromosome frequency and absence of drive in the fish Prochilodus lineatus
}

\author{
CLAUDIO OLIVEIRA* $\uparrow$, SILVIA MARIA RODRIGUES SABOYA $\uparrow$, FAUSTO FORESTI†, \\ JOSÉ AUGUSTO SENHORINI \& GERALDO BERNARDINO \\ †Departamento de Morfologia, Instituto de Biociências, UNESP, 18618-000, Botucatu, SP, Brazil and CAUNESP, and \\ $\ddagger$ Centro de Pesquisa e Treinamento em Aqüicultura, IBAMA, Pirassununga, SP, Brazil
}

\begin{abstract}
The neotropical freshwater fish species Prochilodus lineatus (Pisces, Prochilodontidae) shows $2 n=54$ chromosomes plus supernumerary microchromosomes ranging in number from zero to seven among different animals. The transmission rates of $\mathrm{B}$ chromosomes were studied by the analysis of the parental and $F_{1}$ generations in 10 controlled crosses performed with specimens from a natural population. The mean transmission rate observed for $\mathrm{B}$ chromosomes $\left(k_{\mathrm{B}}=0.511\right)$ was consistent with that expected from a regular meiotic behaviour of Bs in both sexes and with the theoretical value under a Mendelian mode of transmission (0.5). Possible explanations for the dramatic increase in B frequency observed in this population during the last 10 years are discussed, bearing in mind the current absence of drive.
\end{abstract}

Keywords: B chromosome evolution, B chromosomes inheritance, fish cytogenetics, supernumerary chromosomes.

\section{Introduction}

Supernumerary or B chromosomes are found in about 15 per cent of all species of both plants and animals (Jones \& Rees, 1982; Beukeboom, 1994). However, the structure, function and behaviour of these supernumerary chromosomes are quite particular in different groups, making it difficult to reach a general conclusion about their importance for the species.

Despite the fact that only a few studies have been undertaken concerning the inheritance of B chromosomes, almost all the results have demonstrated that they usually show a mechanism of accumulation (drive), which explains their selfish nature (Jones, 1991). However, at least two species, Allium schoenoprasum (Bougourd \& Parker, 1979; Bougourd \& Plowman, 1996) and Eyprepocnemis plorans (LópezLeón et al., 1992), do not show such accumulation mechanisms and represent two cases in which the selfish model is now being submitted to critical test. Whereas Bs in A. schoenoprasum seem to be essentially heterotic because of the advantage of B-carrying plants during seed to seedling development (Holmes \& Bougourd, 1989), B chromosomes in E. plorans were originally selfish but have been neutralized, thus losing drive, by the presence of

*Correspondence. E-mail: foresti@laser.com.br drive-suppressor genes in the A genome (Herrera et al., 1996; Camacho et al., 1997; J. P. M. Camacho et al., unpublished observations).

B chromosomes apparently are not widespread among fishes. Thus, among about 2800 karyotyped species (Klinkhardt et al., 1995), only 40 species with $\mathrm{B}$ chromosomes have been described ( 1.5 per cent). Such a reduced frequency may represent a real situation or, alternatively, may reflect the fact that many of the early cytogenetic studies on fishes were performed on a very small number of specimens and usually employed low-resolution techniques. The first occurrence of B chromosomes among neotropical freshwater fishes was reported by Pauls \& Bertollo (1983) in Prochilodus lineatus ( = P. scrofa), and this species was recently restudied by Cavallaro (1992). Considering that the species $P$. lineatus has been bred successfully in captivity and has been used extensively in aquaculture programmes in Brazil, the objective of the present study was to analyse the mode of inheritance of $\mathrm{B}$ chromosomes in this fish species. No previous studies involving B chromosome inheritance have been performed in fishes, apart from the demonstration of paternal inheritance in the gynogenetic fish Poecilia formosa (Schartl et al., 1995). The results showed an absence of drive for $P$. lineatus $\mathrm{Bs}$, which may provide another useful test for the selfish theory of $B$ chromosome evolution. 


\section{Materials and methods}

Two groups of $P$. lineatus specimens were analysed: the first consisted of 10 couples formed by gamete combination involving six females and 10 males (two females were crossed with two males each and a third female was crossed with three males), captured from a natural population in the Mogi-Guaçu river (Pirassununga, State of São Paulo, Brazil) in 1991/1992; these represented the parental generation. The second group consisted of 131 specimens obtained from the parental generation in controlled crosses and represented the $F_{1}$ generation.

Chromosome preparations from kidney tissue were obtained using the method of Foresti et al. (1993). For the establishment of the modal number of Bs, 30 cells with $2 n=54$ A chromosomes were analysed in each individual. The transmission rate of $\mathrm{B}$ chromosomes $\left(k_{\mathrm{B}}\right)$ was investigated using the Z-test (López-León et al., 1992), and karyotypic frequencies were compared by the nonparametric Kruskal-Wallis and Mann-Whitney tests.

\section{Results}

The present study confirms the diploid number of $2 \mathrm{n}=54$ chromosomes in $P$. lineatus as observed previously by Pauls \& Bertollo (1983) and Cavallaro (1992). The chromosomes of this species are metacentric or submetacentric ranging in size from 2.5 to $5.0 \mu \mathrm{m}$.

The analysis of 16 specimens collected in the Mogi-Guaçu river in 1991/1992 and their $F_{1}$ offspring (131 specimens) showed the presence of zero to seven supernumerary chromosomes of very small size (about $0.7 \mu \mathrm{m}$ ) and very similar morphology (metacentric). As shown in Table 1, previous studies of B chromosome frequency performed on this population by Pauls \& Bertollo (1983) and Cavallaro (1992) on specimens collected in 1979/1980 and 1987/89, respectively, showed a dramatic increase in mean $B$ frequency from 1.341 to 2.766 during this period (Mann-Whitney test: $z=5.18, P<0.0001$ ), whereas the mean number of
Bs was only slightly and nonsignificantly increased between 1987/89 and the present study (MannWhitney test: $z=0.90, P=0.37$ ).

All of the 10 controlled crosses showed an absence of significant drive for the B chromosomes, with a high consistency among crosses (Table 2). The mean rate of $\mathrm{B}$ chromosome transmission $\left(k_{\mathrm{B}}=0.511\right)$ observed in the 10 controlled crosses was consistent with that expected from regular meiotic behaviour of $\mathrm{Bs}$ in both sexes and also closely similar to the 0.5 Mendelian theoretical value.

Therefore, no net accumulation or elimination of B chromosomes seems to exist in $P$. lineatus, which is in accordance with the fact that the mean number of Bs in the $131 \mathrm{~F}_{1}$ progeny analysed (3.212) did not differ significantly from that observed in the 16 adult individuals (3.063) used as the parental generation (Mann-Whitney test: $z=0.17, P=0.86$ ).

However, the possibility that Bs are accumulated in one sex and eliminated in the other cannot be ruled out on the basis of the present results, because all our crosses involved males and females carrying Bs. The high frequency reached by the $\mathrm{B}$ chromosomes, however, virtually prevents the detection of zero $\mathrm{B}$ individuals in the natural population and, hence, it was not possible to analyse uniparental B transmission.

In the present study, the number of cells with B chromosome numbers differing from the modal number for the individual was very low (3.4 per cent), thus indicating a low degree of mitotic instability for the B chromosomes in the natural population of $P$. lineatus from the Mogi-Guaçu river. The same situation was observed by Cavallaro (1992) in the specimens analysed 2 years before. These observations contrast with the high mitotic instability of Bs in this same population reported by Pauls \& Bertollo (1983) in a sample collected about 10 years before, which reached 44.1 per cent. These data suggest either a substitution of the original B chromosome type by a $\mathrm{B}$ variant with a higher mitotic stability or a progressive coadaptation

Table 1 Evolution of B chromosome frequency in the population of Prochilodus lineatus from the Mogi-Guaçu river

\begin{tabular}{|c|c|c|c|c|c|c|c|c|c|c|c|}
\hline \multirow[b]{2}{*}{ Year } & \multicolumn{8}{|c|}{ Number of individuals with } & \multirow[b]{2}{*}{ Total } & \multirow{2}{*}{$\begin{array}{c}\text { Mean no. } \\
\text { of Bs }\end{array}$} & \multirow[b]{2}{*}{ References } \\
\hline & $0 \mathrm{~B}$ & IB & $2 \mathrm{~B}$ & $3 \mathrm{~B}$ & $4 \mathrm{~B}$ & $5 \mathrm{~B}$ & $6 \mathrm{~B}$ & $7 \mathrm{~B}$ & & & \\
\hline $1979-80$ & 18 & 5 & 13 & 6 & 0 & 2 & 0 & 0 & 44 & 1.341 & Pauls \& Bertollo (1983) \\
\hline $1987-89$ & 1 & 11 & 22 & 21 & 15 & 7 & 0 & 0 & 77 & 2.766 & Cavallaro (1992) \\
\hline 1991-92 (parents) & 0 & 0 & 6 & 4 & 5 & 1 & 0 & 0 & 16 & 3.063 & This paper \\
\hline 1991-92 (offspring) & 1 & 5 & 40 & 33 & 39 & 10 & 2 & 1 & 131 & 3.212 & This paper \\
\hline
\end{tabular}


Table 2 Transmission analysis of B chromosomes in controlled crosses involving couples of wild specimens of Prochilodus lineatus

\begin{tabular}{|c|c|c|c|c|c|c|c|c|c|c|c|c|c|c|c|}
\hline \multicolumn{2}{|c|}{$\begin{array}{l}\text { Type of } \\
\text { cross }\end{array}$} & \multirow[b]{2}{*}{ Code } & \multicolumn{9}{|c|}{$\begin{array}{l}\text { Number of specimens from the } F_{1} \text { generation } \\
\text { with modal number of } B s\end{array}$} & \multirow{2}{*}{$\begin{array}{l}\text { Mean } \\
\text { number } \\
\text { of Bs }\end{array}$} & \multicolumn{3}{|c|}{ B transmission } \\
\hline$q$ & o & & 0 & 1 & 2 & 3 & 4 & 5 & 6 & 7 & Total & & $k_{\mathrm{B}}$ & $Z$ & $P$ \\
\hline 2 & 2 & $\mathrm{C} 1$ & 1 & 3 & 14 & 4 & 2 & & & & 24 & 2.1250 & 0.5313 & 0.3062 & NS \\
\hline \multirow[t]{2}{*}{2} & 2 & $\mathrm{C} 2$ & & 2 & 4 & 4 & 1 & & & & 11 & 2.3636 & 0.5909 & 0.6030 & NS \\
\hline & & Total & 1 & 5 & 18 & 8 & 3 & & & & 35 & 2.2000 & 0.5500 & 0.5916 & NS \\
\hline 3 & 3 & C3 & & & 4 & 6 & & 2 & & & 12 & 3.0000 & 0.5000 & 0.0000 & NS \\
\hline \multirow[t]{2}{*}{3} & 3 & $\mathrm{C} 4$ & & & 1 & 2 & 6 & 1 & & & 10 & 3.7000 & 0.6167 & 0.7379 & NS \\
\hline & & Total & & & 5 & 8 & 6 & 3 & & & 22 & 3.3182 & 0.5530 & 0.4975 & NS \\
\hline 4 & 4 & $\mathrm{C} 5$ & & & 1 & 3 & 12 & 1 & & & 17 & 3.7647 & 0.4706 & -0.2425 & NS \\
\hline 2 & 3 & C6 & & & 5 & 6 & & & & & 11 & 2.5455 & 0.5091 & 0.0603 & NS \\
\hline 2 & 4 & $\mathrm{C} 7$ & & & 5 & 1 & 4 & & & & 10 & 2.9000 & 0.4833 & -0.1054 & NS \\
\hline 5 & 2 & $\mathrm{C} 8$ & & & 5 & 3 & 2 & 4 & & & 14 & 3.3571 & 0.4796 & -0.1527 & NS \\
\hline 5 & 4 & $\mathrm{CP}$ & & & & 2 & 4 & 1 & 1 & 1 & 9 & 4.4444 & 0.4938 & -0.0370 & NS \\
\hline \multirow[t]{3}{*}{5} & 4 & $\mathrm{C} 10$ & & & 1 & 2 & 8 & 1 & 1 & & 13 & 3.9231 & 0.4359 & -0.4623 & NS \\
\hline & & Total & & & 1 & 4 & 12 & 2 & 2 & 1 & 22 & 4.1364 & 0.4596 & -0.3790 & NS \\
\hline & Totals & & 1 & 5 & 40 & 33 & 39 & 10 & 2 & 1 & 131 & 3.5442 & 0.5111 & & \\
\hline
\end{tabular}

$k_{\mathrm{B}}$, transmission rate of $\mathrm{B}$ chromosomes. $Z$ indicates significant differences if greater than 1.96 in absolute value. NS, not significant.

between Bs and the host genome, leading to a regularization of the mitotic behaviour of the Bs. In any case, the consequence seems to be the fixation of a mitotically stable B chromosome system in this population.

\section{Discussion}

Studies on the temporal stability of B chromosome polymorphisms have shown that some populations reach a stable frequency over periods from 6 to 9 years (Hewitt \& John, 1967; Jackson \& Cheung, 1967; Kayano et al., 1970). Some populations of mealy bugs (Nur, 1966) and rye (Jones \& Rees, 1982) showed an increase in the number of $B$ chromosomes over some generations, similar to that observed in $P$. lineatus from the Mogi-Guaçu river. On the other hand, a decrease in B frequency was observed in a Japanese rye population under strong selective pressure (Moss, 1966). As pointed out by Jones \& Rees (1982), these examples, taken together, provide strong evidence for a marked influence of varying kinds of selection on B chromosome frequency.

Two kinds of selection may favour the increase in B frequency: (i) phenotypic selection, in which case Bs should be considered 'heterotic' by providing a beneficial effect on carrier fitness (White, 1973); and (ii) nonphenotypic selection, caused by the existence of drive (accumulation mechanisms), in which case Bs should be considered 'selfish', because they would be maintained in natural populations despite being harmful to carriers (see Henriques-Gil \& Arana, 1990). Ascertaining which of these two kinds of selection process is responsible for $\mathrm{B}$ maintenance in natural populations is a major task, demanding extensive investigation in many species. Although most Bs seem to fit the selfish model, there are some cases lacking significant drive, which, at first glance, are good candidates for heterotic Bs. This could be the case for $P$. lineatus Bs in the MogiGuaçu river population, if the increase in frequency from $1979 / 80$ to $1987 / 89$ resulted from a beneficial effect on carriers. Although this interpretation is a possibility that needs to be tested by the analysis of the phenotypic effects of Bs in this species, there is a second possibility that is strongly supported by recent findings in the grasshopper, Eyprepocnemis plorans, in which a $\mathrm{B}$ chromosome lacking drive and phenotypic effects on fitness shows a widespread geographical distribution (Camacho, 1993) that is incompatible with the hypothesis that the $\mathrm{B}$ never had drive. This species provides the first case of a B chromosome that was initially selfish but has been 
neutralized by the evolution of drive-suppressor genes in the A genome (Herrera et al., 1996; Camacho et al., 1997). In P. lineatus, it is possible that the $B$ was selfish in origin, facilitating its initial increase in frequency in the population, that it was still selfish in $1979 / 80$, but that drive had been neutralized by 1991/92. Mitotic instability can be important in B chromosome accumulation (Jones, 1991), so in the present case a reduction in drive may have been accompanied by an increase in mitotic stability.

Further studies analysing (i) B chromosome inheritance in each sex separately, by performing crosses in which one of the parents lacks Bs, (ii) the genetic control of B chromosome transmission, for which purpose interpopulation crosses might be very useful, (iii) the existence of phenotypic fitness effects related to $\mathrm{B}$ presence, and (iv) $\mathrm{B}$ chromosome frequency in many other populations in order to determine large-scale geographical distribution of these Bs, will provide valuable information on the evolutionary significance of this B chromosome polymorphism in natural populations of $P$. lineatus and may contribute to the genetic improvement of lines in breeding programmes.

\section{Acknowledgements}

The authors are grateful to R. Devidé for technical assistance and to Dr Juan Pedro M. Camacho for a critical review of the original manuscript and for his valuable contribution in the statistical analysis. Funds supporting this study were provided by $\mathrm{CNPq}$, FUNDUNESP and FAPESP.

\section{References}

BEUKEBOOM, L. W. 1994. Bewildering Bs: an impression of the 1st B-chromosome conference. Heredity, 73, $328-336$.

BOUGOURD, S. M. AND PARKER, J. S. 1979. The B-chromosome system of Allium schoenoprasum. II. Stability, inheritance and phenotypic effects. Chromosoma, 75, 369-383.

Bougourd, S. M. AND Plowman, A. B. 1996. The inheritance of B-chromosomes in Allium schoenoprasum $\mathrm{L}$. Chromosome Res., 4, 151-158.

CAMACHO, J. P. M. 1993. Polymorphisms and geographic distribution. In: Proceedings of the 1st B-chromosome Conference, Madrid, Spain, pp. 2-3.

CAMACHO, J. P. M., CABRERO, J., LÓPEZ-l.eÓN, M. D. AND SHAW, M. W. 1997. Evolution of a near-neutral B chromosome. Chromosomes Today, 12, 301-318.

Cavallaro., Z. I. 1992. Estudos Comparativos Sobre os Cromossomos $B$ de Prochilodus scrofa Steindachner,
1881 (Pisces, Prochilodontidae) de Diferentes Localidades. Master's thesis. Universidade Federal de São Carlos, São Carlos, SP, Brazil.

FORESTI, F., OliVEIRA, C. AND ALMEIDA-TOLEDO, L. F.. 1993. A method for chromosome preparations from large specimens of fishes using in vitro short treatment with colchicine. Experientia, 49, 810-813.

HENRIQUES-GIL, N. AND ARANA, P. 1990. Origin and substitution of B chromosomes in the grasshopper Eyprepocnemis plorans. Evolution, 44, 747-753.

HERRERA, J. A., LÓPEZ-LEÓN, M. D., CABRERO, J., SHAW, M. W. AND CAMACHO, J. P. M. 1996. Evidence for B chromosome drive suppression in the grasshopper Eyprepocnemis plorans. Heredity, 76, 633-639.

HEWITT, G. M. AND JOHN, B. 1967. The B chromosome system of Myrmelleotettix maculatus (Thunb.) III. The statistics. Chromosoma, 21, 140-162.

HOLmES, D. S. AND BOUGOURD, s. M. 1989. B chromosome selection in Allium schoenoprasum. I. Natural populations. Heredity, 63, 83-87.

JACKSON, W. S. AND CHEUNG, D. S. M. 1967. Distortional meiotic segregation of a supernumerary chromosome producing differential frequencies in the sexes in the short-horned grasshopper Phaulacridium vittatum. Chromosoma, 23, 24-37.

JONES, R. N. 1991. B-chromosome drive. Am. Nat., 137, $430-442$.

IONES, R. N. AND REES, H. 1982. B Chromosomes. Academic Press, London.

KAYANO, H., SANNOMIYA, M. AND NAKUMURA, K. 1970. Cytogenetic studies on natural populations of Acrida lata. I. Local variation in the frequency of B-chromosomes. Heredity, 25, 113-122.

KLinkHardt, M., TESChe, M. ANd GREVEN, H. 1995. Database of Fish Chromosomes. Westarp Wissenschaften, Magdeburg.

LÓPEZ-LEÓN, M. D., CABRERO, J., CAMACHO, J. P. M., CANO, M. I. AND SANTos, J. L. 1992. A widespread B chromosome polymorphism maintained without apparent drive. Evolution, 46, 529-539.

Moss, J. P. 1966. The adaptive significance of B-chromosomes in rye. Chromosomes Today, 1, 15-23.

NUR, U. 1966. Harmful supernumerary chromosomes in a mealy bug population. Genetics, 54, 1225-1238.

PAUls, E. AND BERTOllo, L. A. C. 1983. Evidence for a system of supernumerary chromosomes in Prochilodus scrofa Steindacher 1881 (Pisces, Prochilodontidae). Caryologia, 36, 307-314.

SCHARTL, M., NANDA, 1., SCHLUPP, I., WILDE, B., EPPLEN, J. T., SCHMIDT, M. AND PARZEFALL, J. 1995. Incorporation of subgenomic amounts of DNA as compensation for mutational load in a gynogenetic fish. Nature, 373, $68-71$.

whrte, M. J. D. 1973. Animal Cytology and Evolution, 3rd edn. Cambridge University Press, Cambridge. 